\title{
Thermophysical Properties of Nanomodified Liquids
}

\author{
Ali J. Ali ${ }^{1,2 *}$, E.N. Tugolukov ${ }^{1}$, L.J. Habeeb ${ }^{3}$ \\ ${ }^{1}$ Tambov State Technical University, 106, Sovetskaya ul., Tambov, 392000, Russia; \\ ${ }^{2}$ Department of Biomedical Engineering, University of Technology, Alsina'a Street, Baghdad 10001, Iraq; \\ ${ }^{3}$ Training and Workshop Center, University of Technology, Alsina'a St., Baghdad 10001, Iraq \\ *Corresponding author. Tel.: +7 91588177 06.E-mail: eng_ali_jalal80@mail.ru
}

\begin{abstract}
This paper attempts to determine thermophysical properties such as density, heat capacity and thermal conductivity for four types of nanoparticle suspension in water by using theoretical models. Three concentrations of $0.01,0.05$ and 0.1 wt. $\%$ nanoparticles were used at temperatures 35,40 and $45^{\circ} \mathrm{C}$. It also attempts to present the properties of (CNT Taunit M) and the method of its preparation. It was observed that thermal conductivity and density increased, and contrariwise, specific heat decreased with an increase in volume concentration at various temperatures.
\end{abstract}

Keywords

Carbon nanotubes; Taunit M; Nanofluid; thermal conductivity; nanomaterials; thermophysical.

(C) Ali J. Ali, E.N. Tugolukov, L.J. Habeeb, 2020

\begin{tabular}{ll} 
& \multicolumn{1}{c}{ Nomenclature } \\
CNTs & Carbon nanotubes; \\
MWCNT & Multi Wall Carbon Nanotube; \\
DWCNT & Double Wall Carbon Nanotube; \\
SWCNT & Single Wall Carbon Nanotube; \\
$n f$ & Nanofluid; \\
$P$ & Weight, $\mathrm{kg} ;$ \\
$n p$ & Nano particle; \\
$b f$ & Base fluid; \\
$\varphi$ & Volume concentration, $\mathrm{m}^{3} / \mathrm{m}^{3} ;$ \\
$c$ & Mass concentration, $\mathrm{kg} / \mathrm{m}^{3} ;$ \\
$\mu$ & Dynamic viscosity, $\mathrm{N} \cdot \mathrm{c} / \mathrm{m}^{2} ;$ \\
$C p$ & Specific heat, $\mathrm{J} /(\mathrm{kg} \cdot \mathrm{K}) ;$ \\
$\rho$ & Density, $\mathrm{kg} / \mathrm{m}^{3} ;$ \\
$\lambda$ & Thermal conductivity, $\mathrm{W} /(\mathrm{m} \cdot \mathrm{K}) ;$ \\
$V$ & Voltage, V; \\
$I$ & Current, A.
\end{tabular}

\section{Introduction}

Improvement of the thermal performance of the heat transferring fluids plays a pivotal role because of the achieved benefits like reducing surface area of heat exchange, minimizing cost, reducing drawn power and maintaining on the application life. Generally, the heat transfer coefficient of these fluids, such as water, oil, ethylene glycol (EG) or ethylene glycol-water is low because of their lower thermal conductivity comparison with the solid materials that have high thermal conductivity by tens or hundred times [1]. Blending a little amount of small solid particles with a host fluid can push the fluid possibilities to its limitation in the heat transferring performance.

This idea was introduced by Maxwell at (1873) when he used micrometer and millimeter particles size with a host fluid, but from among the obstacles that appeared were the fast settling, channel clogging, parts erosion and high pressure drop [2]. At 1995, the "Nanofluid" term appeared officially by Choi and Eastman [3] when they experimentally investigated the suspension of copper oxide-water $\left(\mathrm{CuO}-\mathrm{H}_{2} \mathrm{O}\right)$ and aluminum oxide-ethylene glycol/water nanofluid $(n f)$ $\left(\mathrm{Al}_{2} \mathrm{O}_{3}-\mathrm{EG} / \mathrm{H}_{2} \mathrm{O}\right)$, the results showed a thermal augmentation by $20 \%$ in the heat transfer. Also, they demonstrated the term "effective thermal conductivity $\left(k / k^{\circ}\right)$, which means the ratio between nanofluid to base fluid thermal conductivity. So, the nanofluid is a new brand of fluids and could be defined as a suspension consisting of a host fluid and nanoparticles sized less than $\left(100 \times 10^{-9}\right)$ meter [4]. As shown in Fig. 1. This study will focus on the thermal properties of four types of nanofluids $\left(\mathrm{Al}_{2} \mathrm{O}_{3}, \mathrm{CuO}, \mathrm{CNT}\right.$ (Carbon Nanotubes) tauint mand $\mathrm{TiO}_{2}$ ) in water are measured numerical by using theoretical models. Results were compared with numerical data available in the literature. 


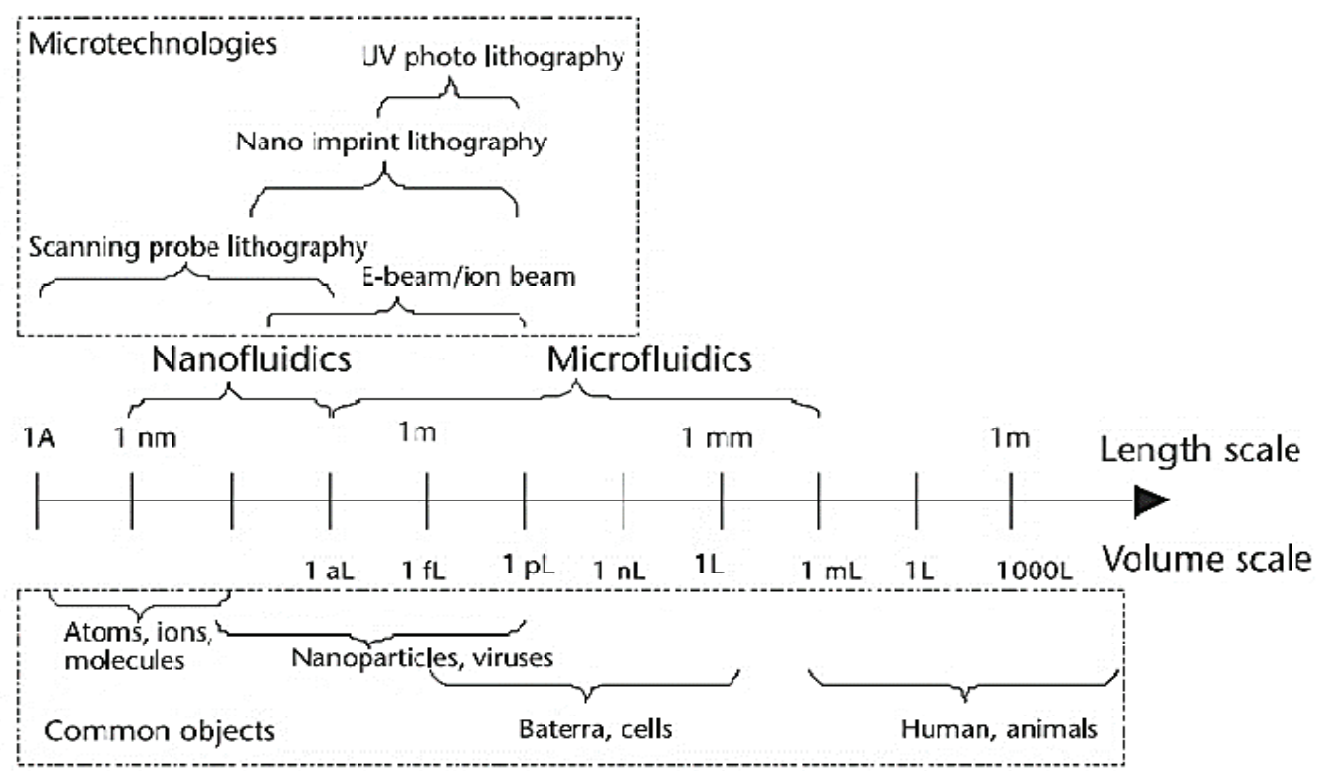

Fig. 1. Length scales and volume scales of nanofluidics, microfluidics, common micro technologies, and common objects [5]

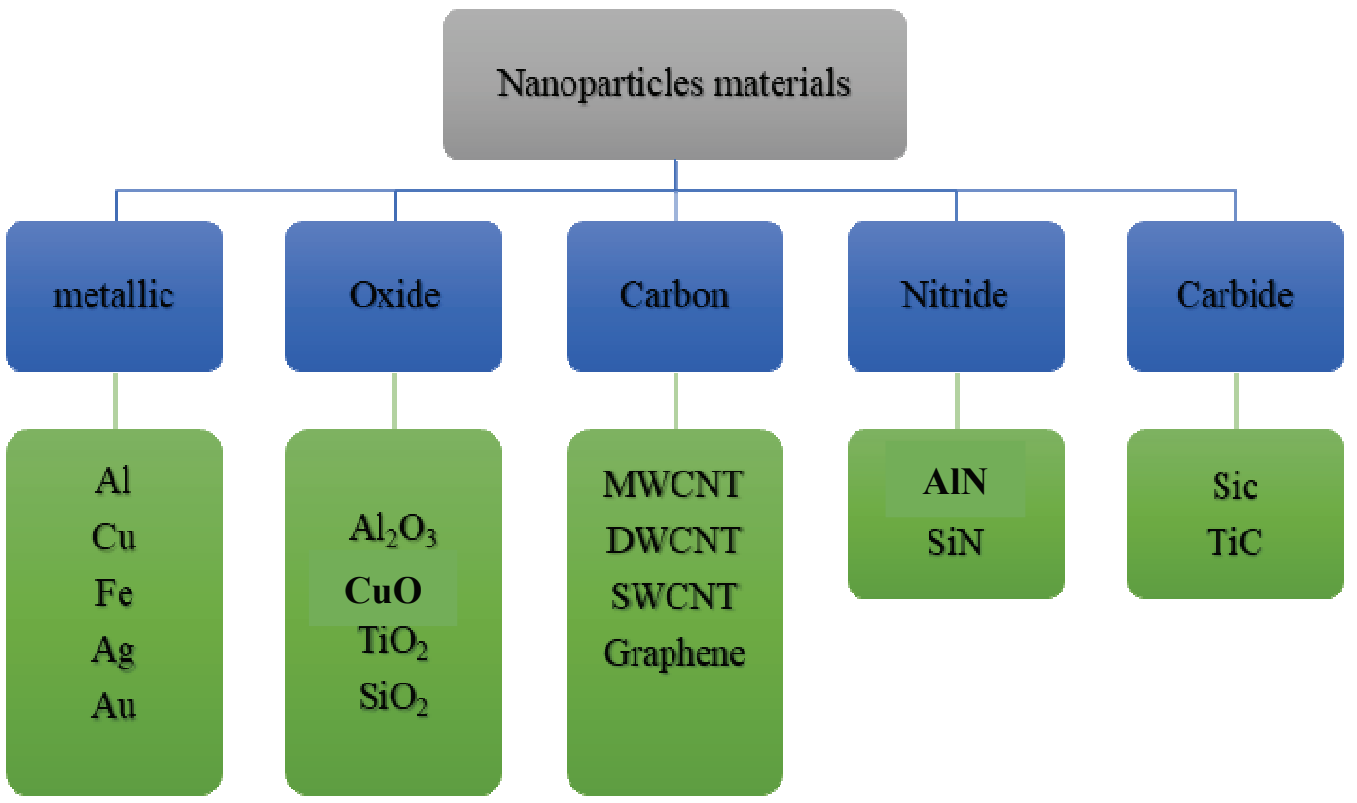

Fig. 2. Nanoparticles materials types $[8,9]$

\section{Nanomaterials}

The types of nanomaterials that form the nanofluids are metal, metal oxide, carbon, carbides and nitride and the selection of any type from them is not a random process but it is based on some governing characteristics that should be met; thermal conductivity, viscosity and density in addition to obtainable, poisonous, chemical behavior and cost [6]. The widely used material in the nanofluid field is the metal oxides in spite of higher thermal conductivity of metal due to the metal oxides characterized by their lower density which reduce the settling, also they have resistance against the oxidation [7]. Moreover, most studies are utilizing aluminum oxide intensively between all the metal oxides because it has low density and high thermal conductivity [6] as shown in Fig. 2.

\section{Base fluid}

To create nanofluid, nanoparticles must be mixed in certain method withbase fluid, such as water, Fat, Ethylene glycol (EG), Engine Oil (EO) and others at different volume or weight concentrations. 
The advantages of using nanofluids are as follows:

- minimal pressure drop because of nanoparticles dimensions;

- thermal conductivity has higher value than the base fluid and that will increase the heat transfer rate;

- small and most efficient heat exchangers can be used;

- a remarkable change in the properties of the base fluid, by suspending the nanoparticles in base fluid;

- increased heat transfer rate due to the large surface area of the nanoparticles in the base fluid;

- appropriate for cooling processing systems and fast heating;

- fluid is considered as integral fluid because of nanoparticles size. follows:

The disadvantages of using nanofluids are as

- high nanoparticles cost;

- toxicity of some types of nanoparticles and the risk of exposure to the body due to the nanosized particles;

- deposition and aggregation of nanotubes through nanofluid.

\section{Transport Properties and Thermophysical Properties}

The thermal conductivity of nanofluids has been thoroughly studied and other properties since the beginning of nanofluid. The researchers reported perfect improvement in this area. Also, other properties that could be as essential as the thermal conductivity, such as viscosity, heat transfer coefficient, specific heat, and heat transfer coefficient. All of them were directly influenced by the addition of nanoparticles. But this improvement also depends on several parameters as (volume fraction (vol. \%), thermal conductivity of nanoparticles and base fluid, size of nanoparticles, shape of the nanoparticles, acidity, temperature, aspect ratio, additives, and effect of clustering). It worth noting that the improvement may occur to one property and other properties could have a negative impact. For instance, the thermal conductivity could get high improvement, but the viscosity increases to inadmissible level and leads to a high-pressure drop and high pumping power consumption. Therefore, the overall improvement in all relevant properties must be balanced and taken into consideration.

One of the problems in nanofluid technology is the agglomeration of nanoparticles after different time periods. Three methods have been used to avoid sedimentation of nanoparticles and to obtain a stable suspension $[10-13]$ :
1) a chemical method by adding surfactants;

2) a physical method using ultrasonic waves at different;

3) an electrical method by controlling the $\mathrm{pH}$.

\section{Applications of nanofluids}

Nanofluids have distinct thermophysical properties, to be effective in many various areas and industries; there are many examples available in the literature [14-22] as shown in Table 1.

\section{Safety Precautions}

Nanoparticles and nanofluids are small in size, making them dangerous to use and touch the human body, it is therefore important to protect the body from these small particles using gloves as well as breathing respirators because of the seriousness of these particles and eye protective glasses from the impact of nanocrystal, as shown in Fig. 3 [23].

\section{Mechanisms of Heat Conduction in Nanofluids}

The reality is that the traditional theory cannot predict the substantially higher value thermal conductivity of nanofluids. In many experiments, it has inspired efforts to identify possible mechanisms based on a variety of empirical observations and some numerical simulation. The proposed mechanisms are usually divided into two groups: dynamic mechanisms and static.

Table 1

Applications of nanofluids

\begin{tabular}{|c|c|c|}
\hline No. & Category & Application \\
\hline 1 & Electronics & Heat pipe, micro channel \\
\hline 2 & Engines & Automobile radiator, fuel \\
\hline 3 & Tribological & $\begin{array}{l}\text { Engine oil, lubricants, } \\
\text { transformers, grinding }\end{array}$ \\
\hline 4 & Aero and defense & $\begin{array}{l}\text { Weapons, radars and } \\
\text { electronics of military }\end{array}$ \\
\hline 5 & Power plants & Boilers, condensers \\
\hline 6 & HVAC & Chillers, air conditioning unit \\
\hline 7 & Refrigeration & Domestic refrigerator \\
\hline 8 & Alternative energy & Solar energy \\
\hline 9 & Biomedical & $\begin{array}{l}\text { Tumors treatment and drug } \\
\text { or radiation delivery }\end{array}$ \\
\hline 10 & Others & $\begin{array}{l}\text { Industry of textile, printing } \\
\text { of paper and food }\end{array}$ \\
\hline
\end{tabular}




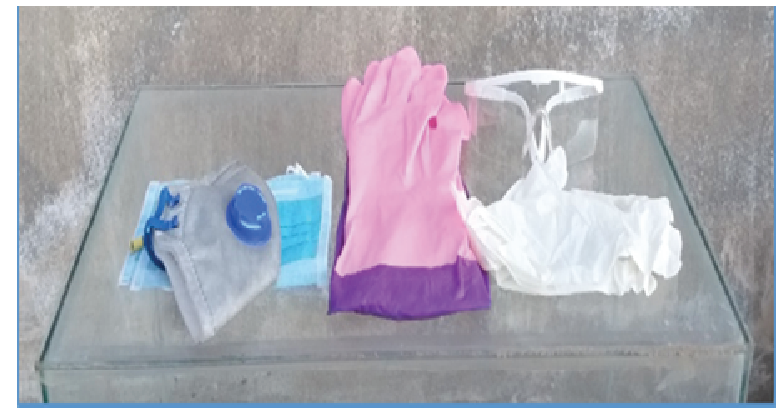

Fig. 3. Safety kit

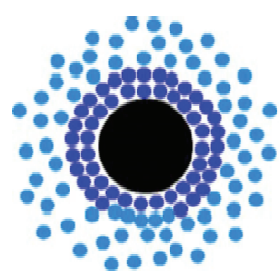

a)

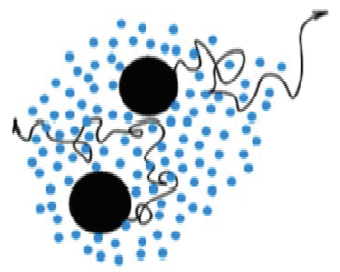

c)

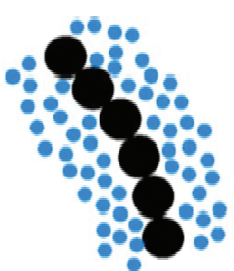

b)

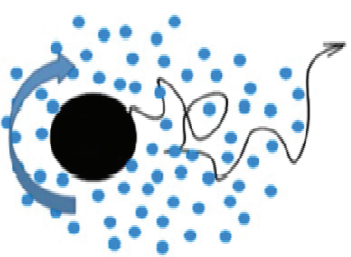

d)
Fig. 4. Four potential mechanisms responsible for the reported conductivity enhancement:

$a$ - liquid-layering; $b$ - particle aggregation; $c$ - particle Brownian motion; $d$ - Brownian-motion-induced convection

Two popular static or structural mechanisms are the liquid-layering at the liquid-particle interface as heat transfer bridge as shown in Fig. 4a. Also, the particle aggregation forms a chainlike thermal transport path is shown in Fig. $4 b$. Figure $4 c$ shows the dynamic mechanisms include the particle Brownian motion. Convection in the foundation liquid caused by the particle Brownian motion is shown in Fig. $4 d$ [24-32].

\section{Preparation of (Taunit $M$ ) nanofluid}

The specifications of the used functionalized carbon nanotubes (FCNT Taunit M) nano powder are listed in Table 2 nanostructured materials manufactured at (NanoTechCenter Ltd.) in Tambov, Russia.

The used nanofluid in this project was prepared by two step method. As the nanofluid is not an ordinary mixture, the following steps are considered through the preparation stages:

1. Calculation of volume fraction of the nanopowder functionalized carbon nanotubes (FCNT
Taunit M) and the base fluid $\left(\mathrm{H}_{2} \mathrm{O}\right)$ for each concentration from the equation [34]:

$$
\varphi=\frac{P_{\text {nano particle }}}{\rho_{\text {nano particle }}} \frac{\rho_{\text {nano particle }}+\frac{P_{\text {water }}}{\rho_{\text {water }}}}{c=\frac{P_{\text {nano particle }}}{P_{\text {nano particle }}+P_{\text {water }}} \times 100 .}
$$

2. An electronic compact scale BEURER (KS 36) manufactured by BDLT company - Germany was used for weighing the required water with range $(0.00-2500.00 \mathrm{~g})$, while another electronic scale made by Citizen scale model CNETEK (CT-2460) with range $(0.00-300.00 \mathrm{~g})$ was used for weighing the required nano powder, as shown in Fig. 5.

3. Adding the nanopowder to the base fluid (distilled water) in the preparation cans, as shown in Fig. 6.

Table 2

Properties of Taunit $M$ functionalized CNTs [33]

\begin{tabular}{lc}
\hline \multicolumn{1}{c}{ Parameter } & Value \\
\hline Outer diameter, $\mathrm{nm}$ & $8-15$ \\
Inner diameter, $\mathrm{nm}$ & $4-8$ \\
Length, $\mu \mathrm{m}$ & 2 and more \\
$\begin{array}{l}\text { Total amount of impurities, } \\
\%,(\text { after purification) }\end{array}$ & up to 5 \\
$\begin{array}{l}\text { Bulk density, } \text { g/cm } \\
\text { Specific geometrical surface, }\end{array}$ & up to 1 \\
$\mathrm{~m}^{2} / \mathrm{g}$ & $0.03-0.05$ \\
$\begin{array}{l}\text { Adsorption activity } \\
\text { methylene blue, } \mathrm{mg} / \mathrm{g}\end{array}$ & $180-200$ \\
$\begin{array}{l}\text { Thermal stability, }{ }^{\circ} \mathrm{C} \\
\text { Color }\end{array}$ & up to 600 \\
\hline
\end{tabular}
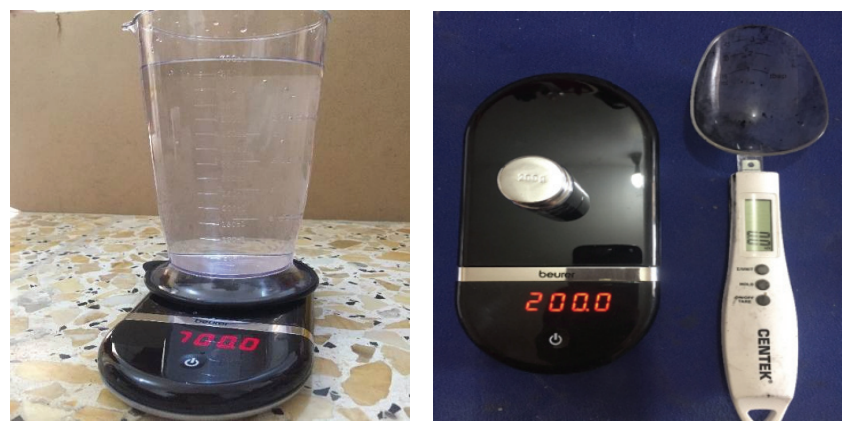

Fig. 5. Water scale and nanopowder scale 


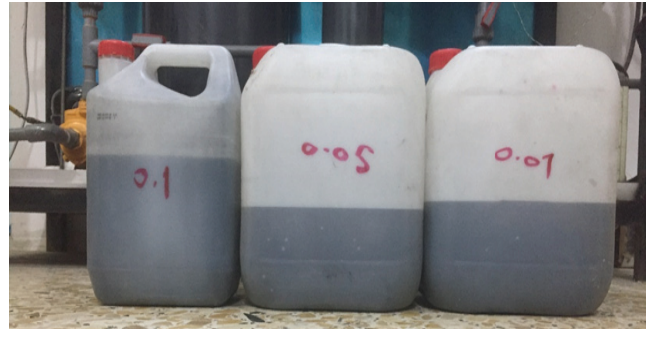

Fig. 6. Preparation cans

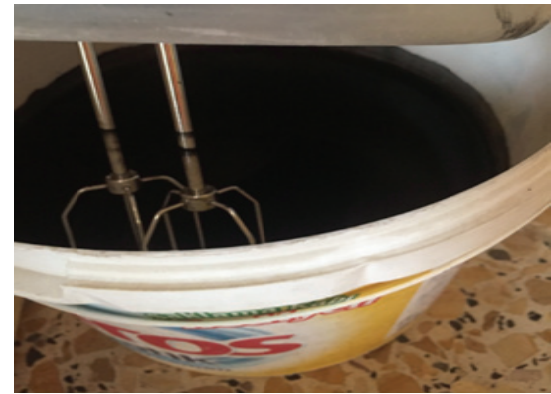

Fig. 7. Hand mixer

4. The mixture was blended model GOSONIC (GHM-819) 300W for 30 minutes by the stirrer, as shown in Fig. 7.

\section{Thermophysical properties calculations sample}

This section includes a sample for theoretical and experimental thermophysical properties calculations of functionalized carbon nanotubes (FCNT Taunit M) nanofluid with $12 \mathrm{~nm}$ particle size and $(0.1,0.05,0.01)$ as volume concentration.

\section{Density calculation}

Theoretically: The nanofluid density is calculated theoretically straight forward from the mixture equation [35]:

$$
\rho_{n f}=\varphi \rho_{n p}+(1-\varphi) \rho_{b f} .
$$

Experimentally:

$$
\rho_{n f}=\frac{w_{2}-w_{1}}{v} .
$$

\section{Viscosity calculation}

Theoretically: The theoretical viscosity is calculated according to Batchelor model [35]:

$$
\mu_{n f}=\left(1+2.5 \varphi+6.2 \varphi^{2}\right) \mu_{b f} .
$$

Experimentally:

$$
\begin{aligned}
& \vartheta_{n f}=c \times t \times 10^{-6} ; \\
& \mu_{n f}=\vartheta \times \rho_{n f} .
\end{aligned}
$$

\section{Specific heat calculation}

Theoretically: The specific heat of the nanofluid was calculated theoretically directly based on the familiar relation of mixture principles [33]:

$$
C p_{n f}=\frac{(1-\varphi)(\rho C p)_{b f}+(\varphi \rho C p)_{p}}{(1-\varphi)(\rho)_{b f}+(\varphi \rho)_{p}} .
$$

\section{Experimentally:}

$$
I V t=m_{n f} C p_{n f} \Delta T+m_{v} C p_{v} \Delta T .
$$

\section{Thermal conductivity calculation}

Theoretically: Maxwell correlation was used to calculate the theoretical thermal conductivity [35]:

$$
k_{n f}=k_{b f}\left[\frac{\left(k_{p}+2 k_{b f}\right)+2 c\left(k_{p}-k_{b f}\right)}{\left(k_{p}+2 k_{b f}\right)-c\left(k_{p}-k_{b f}\right)}\right] .
$$

Experimentally: The experiment data were measured by the device of thermal conductivity measurement KD2-por [36, 37], as shown in Fig. 8.

$$
k=\frac{q\left(\ln t_{2}-\ln t_{1}\right)}{4 \pi\left(\Delta T_{2}-\Delta T_{1}\right)} .
$$

\section{Results and Discussion}

The thermophysical properties of nanofluids with different types of nanoparticles as a function of concentration were calculated. According to the theoretical models, Maxwell correlation was used to calculate the theoretical thermal conductivity and other models was used to calculate the theoretical specific heat and density. The Batchelor correlation was used to calculate the theoretical viscosity. In this paper, because of the low concentrations used that can be neglected it was as follows: 0.1, 0.05, and 0.001 . Thermophysical properties of oxide nanoparticles with (Taunit M) were shown in Table 3. In addition, thermophysical properties of water at 35,40 and $45^{\circ} \mathrm{C}$ were given in Table 4. With different nanoparticles, as water-based nanofluids such as $\mathrm{Al2O} 3$-water, $\mathrm{CuO}$-water, $(\mathrm{CNT}$ taunit $\mathrm{M})$ - water and $\mathrm{TiO}_{2}$-water, at temperature 35,40 and $45{ }^{\circ} \mathrm{C}$ an increase in thermal conductivity and decrease in the heat capacity of nanofluid was observed (Fig. 9 -11). 


\section{AM\&T}

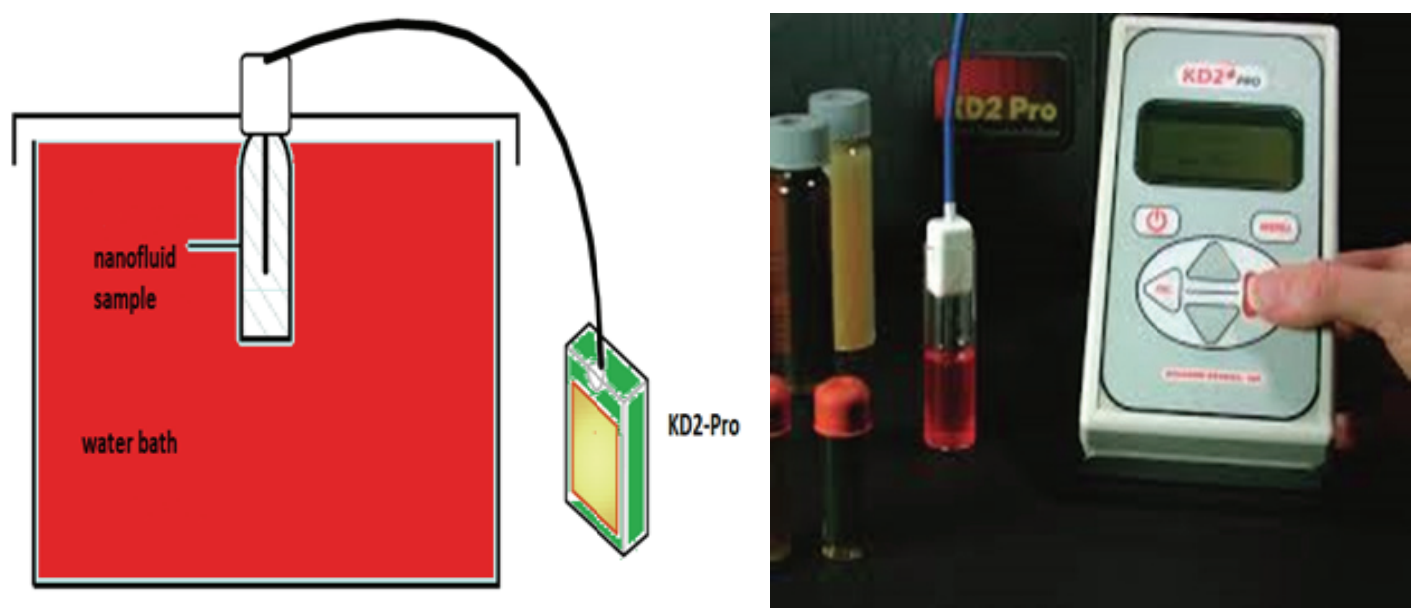

Fig. 8. KD2-por [36]

Table 3

Thermophysical properties of oxide nanoparticles with Taunit M [38 - 40]

\begin{tabular}{lccc}
\hline \multicolumn{1}{c}{ Thermophysical properties } & Specific heat $C p$ & Density $\rho$ & Thermal Conductivity $\lambda$ \\
\hline Copper oxide $(\mathrm{CuO})$ & 535.5 & 6500 & 76 \\
Alumina oxide $\left(\mathrm{Al}_{2} \mathrm{O}_{3}\right)$ & 765 & 3970 & 40 \\
Titanium dioxide $\left(\mathrm{TiO}_{2}\right)$ & 686.2 & 4250 & 8.5 \\
Functionalized $\mathrm{CNTs}($ Taunit $\mathrm{M})$ & 600 & 1500 & 3000 \\
\hline
\end{tabular}

Thermophysical properties of water at 35,40 and $45^{\circ} \mathrm{C}[41,42]$

Table 4

\begin{tabular}{ccccc}
\hline $\begin{array}{c}\text { Thermophysical properties } \\
\text { of water at } 35 \text { and } 40 \text { and } 45^{\circ} \mathrm{C}\end{array}$ & $C p$ & $\rho$ & $\lambda$ & $\mu$ \\
\hline 35 & 4178 & 994.0 & 0.623 & $0.720 \cdot 10^{-3}$ \\
40 & 4179 & 992.1 & 0.631 & $0.653 \cdot 10^{-3}$ \\
45 & 4180 & 990.1 & 0.637 & $0.596 \cdot 10^{-3}$ \\
\hline
\end{tabular}
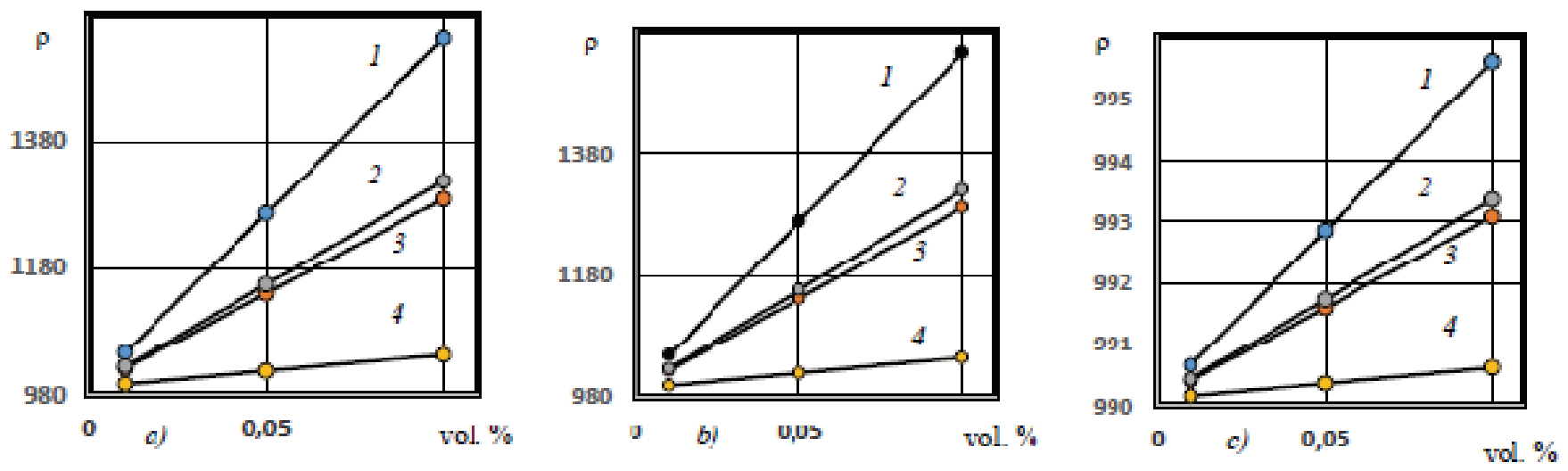

Fig. 9. Density for $n f$ vs. vol. $\%$ at $35(a), 40(b)$ and $45(c),{ }^{\circ} \mathrm{C}$ :

$1-\mathrm{CuO} ; 2-\mathrm{TiO}_{2} ; 3-\mathrm{Al}_{2} \mathrm{O}_{3} ; 4-\mathrm{CNT}$ (Taunit M) 

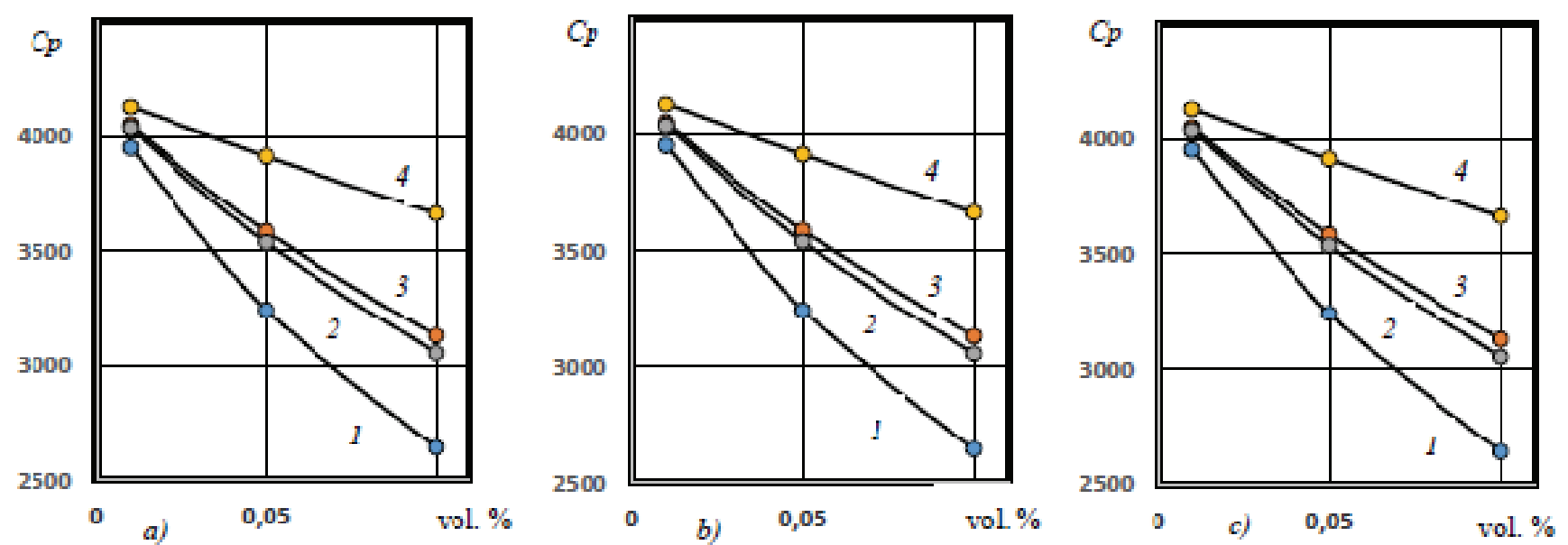

Fig. 10. Specific heat for $n f$ vs. vol. $\%$ at $35(a), 40(b)$ and $45(c),{ }^{\circ} \mathrm{C}$ :

$1-\mathrm{CuO} ; 2-\mathrm{TiO}_{2} ; 3-\mathrm{Al}_{2} \mathrm{O}_{3} ; 4-\mathrm{CNT}$ (Taunit $\mathrm{M}$ )
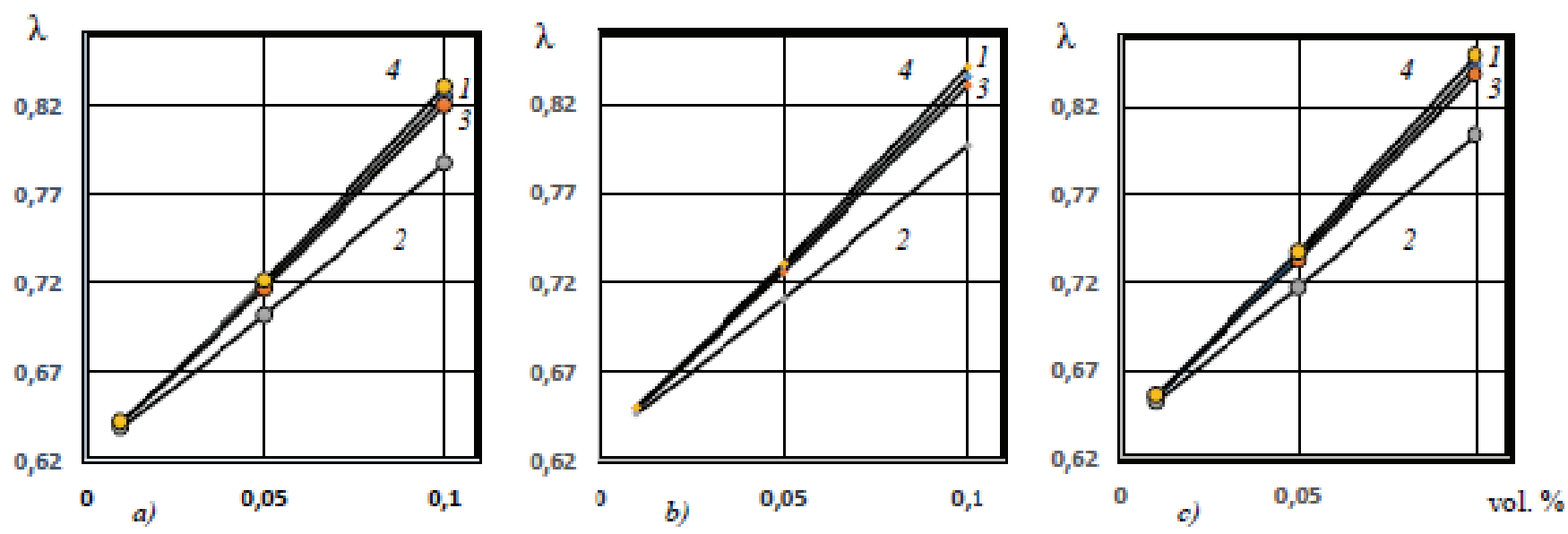

Fig. 11. Termal conductivity for $n f$ vs. vol. $\%$ at $35(a), 40(b)$ and $45(c),{ }^{\circ} \mathrm{C}$ : $1-\mathrm{CuO} ; 2-\mathrm{TiO}_{2} ; 3-\mathrm{Al}_{2} \mathrm{O}_{3} ; 4-\mathrm{CNT}$ (Taunit $\mathrm{M}$ )

\section{Conclusion}

In this paper, we investigated the thermophysical properties of nanofluids with different types of nanoparticles that were suspended in a base fluid (water) measured numerically. Also, the effect of various concentrations at different temperatures was measured. In this paper, the following points could be concluded:

1. Thermal conductivity and density always increased with the increasing volume concentration at various temperatures.

2. Specific heat significantly decreased with the increasing volume concentration at various temperatures.

3. Results showed that CNT (Taunit) of nanofluid has the highest value of thermal coundivity followed by $\mathrm{CuO}$ and $\mathrm{Al}_{2} \mathrm{O}_{3}$; finally, $\mathrm{TiO}_{2}$ had the lowest.
4. Results showed that $\mathrm{CuO}$ of nanofluid has the highest value of denisty followed by $\mathrm{TiO}_{2}$ and $\mathrm{Al}_{2} \mathrm{O}_{3}$; finally, CNT (Taunit) had the lowest.

In this paper, the numerical results showed a good agreement with those obtained in other studies.

\section{References}

1. Keblinski P., Phillpot S.R., Choi S.U.S., \& Eastman J.A. Mechanisms of heat flow in suspensions of nano-sized particles (nanofluids). International journal of heat and mass transfer, 2002, 45(4), 855-863.

2. Maxwell Clerk J. A Treatise on Electricity and Magnetism, 1892, vol. 2, Maxwell Clarendon.

3. Eastman J.A., Choi S.U.S., Li S., Yu W., Thompson L.J. Anomalously increased effective thermal conductivities of ethylene glycol-based nanofluids containing copper nanoparticles. Applied physics letters, 2001, 78(6), 718-720.

4. Hasan S. Review on nanoparticles: their synthesis and types. Research Journal of Recent Sciences, 2014, 4, 1-3. 

House.

5. Abgrall P., Nguyen N. T. Nanofluidics, 2009, Artech

6. Suganthi K.S., Rajan K.S. Metal oxide nanofluids: Review of formulation, thermo-physical properties, mechanisms, and heat transfer performance. Renewable and Sustainable Energy Reviews, 2017, 76, 226-255.

7. Suganthi K.S., Rajan K.S. Temperature induced changes in $\mathrm{ZnO}$ - water nanofluid: Zeta potential, size distribution and viscosity profiles. International Journal of Heat and Mass Transfer, 2012, 55,. 7969-7980.

8. Cain D., Duffy, J. An experimental investigation of turbulent flow in elliptical ducts. International Journal of Mechanical Sciences, 1971, 13(5), 451-459.

9. Choi S.U.S. Nanofluid Technology: Current Status and Future Research. United States: N. p., 1998.

10. Nikkam N. Engineering Nanofluids for Heat Transfer Applications (Doctoral dissertation, KTH Royal Institute of Technology), 2014.

11. Yu W., Xie H. A review on nanofluids: preparation, stability mechanisms, and applications. Journal of nanomaterials, 2012, 1.

12. Mukherjee S., Paria S. Preparation and stability of nanofluids - A Review. IOSR Journal of Mechanical and civil engineering, 2013, 9(2), 63-69.

13. Chen W., Zou C., Li X., Liang H. Application of recoverable carbon nanotube nanofluids in solar desalination system: An experimental investigation. Desalination, 2019, 451, 92-101.

14. Tugolukov E.N., Al-Sharif A.J., Dyachkova T.P., Burakova E.A. Investigation of the Thermal Conductivity of Nanomodified Liquids. Transactions of the Tambov State Technical University, 2019, 25(4), 671-677. (In Russ., abstract in Eng.)

15. Aladinskiy A.A., Rukhov A.V., Tugolukov Ye.N., D'yachkova T.P. Improving the processes and instrumentation of the synthesis of Taunit carbon nanomaterials. Transactions of the Tambov State Technical University, 2014, 20(3), pp. 572-578. (In Russ., abstract in Eng.)

16. Saleh H., Alali E., Ebaid A. Medical applications for the flow of carbon-nanotubes suspended nanofluids in the presence of convective condition using Laplace transform. Journal of the association of Arab universities for basic and applied sciences, 2017, 24(1), 206-212.

17. Mishra P.C., Nayak S.K., Mitra P., Mukherjee S., Paria S. Application and future of nanofluids in automobiles: an overview on current research. Proceedings of 2 nd KIIT International Symposium on Advances in Automotive Technology, 2013.

18. Buongiorno J., Hu L.W., Kim S.J., Hannink R., Truong B.A.O., Forrest E. Nanofluids for enhanced economics and safety of nuclear reactors: an evaluation of the potential features, issues, and research gaps. Nuclear Technology, 2008, 162(1), 80-91.

19. Gupta H.K., Agrawal G.D., Mathur J. An overview of Nanofluids: A new media towards green environment. International Journal of environmental sciences, 2012, 3(1), 433-440.
20. Borbath I., Kacso Z., David L., Potencz I., Bica D., Marinică O., Vèkás L. Applications of magnetic nanofluids in rotating seals. Convergence of micro- and nanoengineering, Bucharest, 2006, 200-210.

21. Akbar N.S., Abid S.A., Tripathi D., Mir N.A. Nanostructures study of CNT nanofluids transport with temperature-dependent variable viscosity in a muscular tube. The European Physical Journal Plus, 2017, 132(3), 110.

22. Phan N.M., Bui H.T., Nguyen, M.H., Phan, H.K. Carbon-nanotube-based liquids: a new class of nanomaterials and their applications. Advances in Natural Sciences: Nanoscience and Nanotechnology, 2014, 5(1), 015-014.

23. Haynes H., Asmatulu R. Nanotechnology Safety in the Aerospace Industry in nanotechnology. Safety, 2013, 85-97.

24. Hone J. Carbon nanotubes: thermal properties. Dekker Encyclopedia of Nanoscience and nanotechnology, 2004, 603-610.

25. Shiomi J., Maruyama S. Diffusive-ballistic heat conduction of carbon nanotubes and nanographene ribbons. International Journal of Thermophysics, 2010, 31(10), 1945-1951.

26. Murshed S.M.S., Leong K.C., Yang C. Enhanced thermal conductivity of $\mathrm{TiO}_{2}$-water based nanofluids. International Journal of thermal sciences, 2005, 44(4), 367-373.

27. Kim S.H., Choi S.R., Kim D. Thermal conductivity of metal-oxide nanofluids: particle size dependence and effect of laser irradiation. Journal of Heat Transfer, 2007, 129(3), 298-307.

28. Prasher R., Bhattacharya P., Phelan P.E. Thermal conductivity of nanoscale colloidal solutions (nanofluids). Physical review letters, 2005, 94(2), 025901.

29. Evans W., Fish J., Keblinski P. Role of Brownian motion hydrodynamics on nanofluid thermal conductivity. Applied Physics Letters, 2006, 88(9), 093116.

30. Domingues G., Volz S., JoulainK., Greffet J.J. Heat transfer between two nanoparticles through near field interaction. Physical review letters, 2005, 94(8), 085901.

31. Ben-Abdallah P. Heat transfer through near-field interactions in nanofluids. Applied physics letters, 2006, 89(11), 113-117.

32. Choi S.U.S., Zhang Z.G., Yu W., Lockwood F.E., Grulke E.A. Anomalous thermal conductivity enhancement in nanotube suspensions. Applied physics letters, 2001, 79(14), 2252-2254.

33. Information on: http://www.nanotc.ru

34. Hussein A.M., Sharma K.V., Bakar R.A., \& Kadirgama K. The effect of nanofluid volume concentration on heat transfer and friction factor inside a horizontal tube. Journal of Nanomaterials, 2013, 1 .

35. Wang X.Q., Mujumdar A.S. A review on nanofluids-part I: theoretical and numerical investigations. Brazilian Journal of Chemical Engineering, 2008, 25(4), 613-630.

36. Sajid M.U., Ali H.M. Thermal conductivity of hybrid nanofluids: a critical review. International Journal of Heat and Mass Transfer, 2018, 126, 211-234. 
37. Chandrasekhar M., Suresh S., Bose A.C. Experimental investigations and theoreticaldetermination of thermal conductivity and viscosity of $\mathrm{Al}_{2} \mathrm{O}_{3}$ /water nanofluid. Experimental Thermal and Fluid Science, 2010, 34(2), 210-216.

38. Mehta A.V., Patel N.M., Tantia D.K., Jha N.M. Mini heat exchanger using Al2O3-water based nanofluid. International Journal of Mechanical Engineering and Technology, 2012, 4(2), 238-244.

39. Nait Bouda F. The onset of Thermal instability of a two-dimensional boundary layer stagnation point flow of a nanofluid. Proceedings of Congrès français de mécanique. AFM, Courbevoie, France (FR), 2013, December.

40. Rashidi S., Karimi N., Mahian O., Esfahani J.A. A concise review on the role of nanoparticles upon the productivity of solar desalination systems. Journal of Thermal Analysis and Calorimetry, 2019, 135(2), 1145-1159.

41. Holman J.P. (2009). Heat Transfer. McGraw-Hill Education.

42. Cengel Y., Cimbala J. Fluid Mechanics Fundamental and applications: Third Edition. McGraw-Hill Higher Education, 2013.

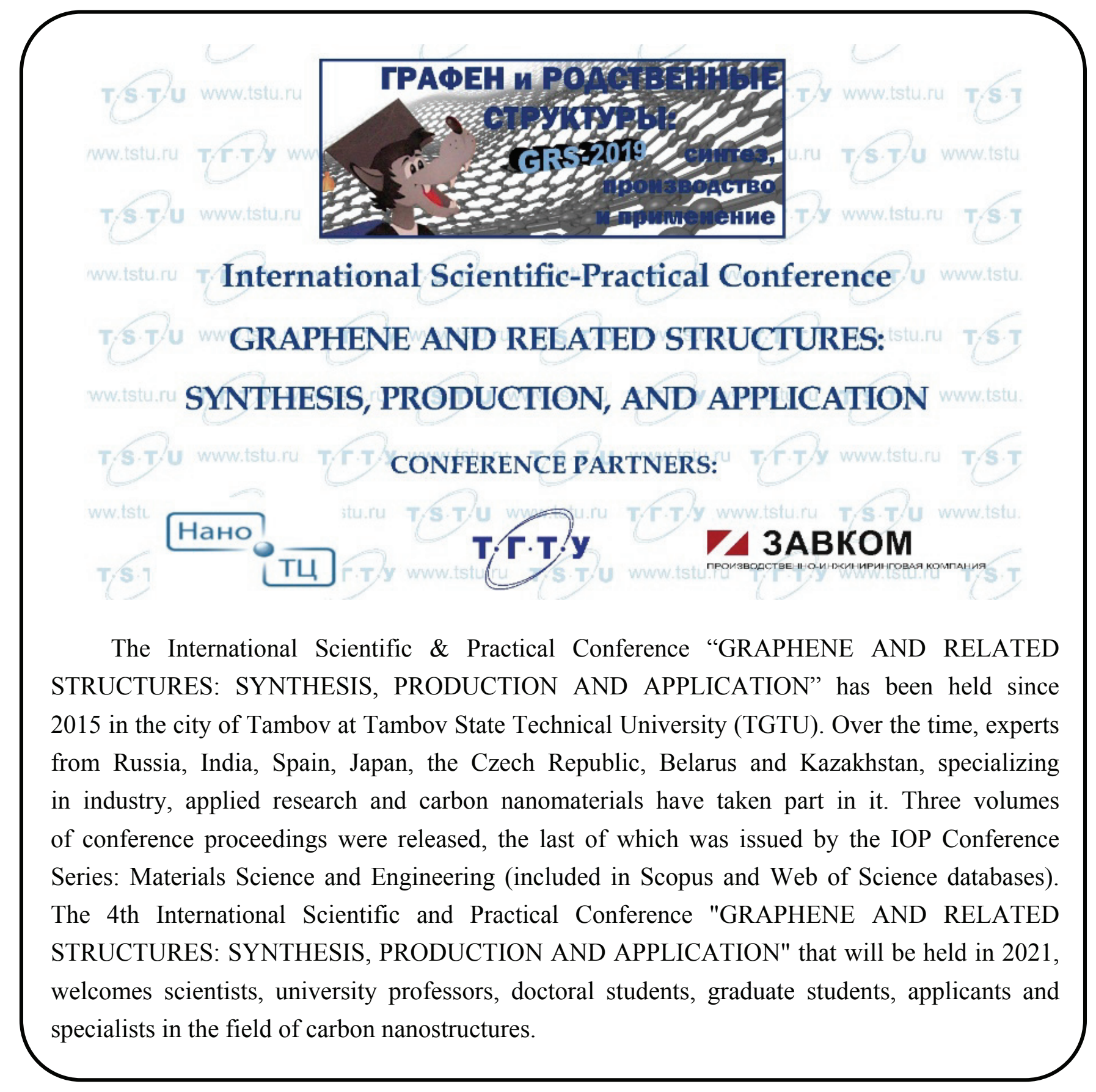

